\title{
Sensitivity of micromycetes of the genus Fusarium Link, causative agents of rot of the core of apple fruits, to the active substances of modern fungicides
}

\author{
Galina Yakuba*, Irina Astapchuk, and Andrey Nasonov \\ Federal State Budget Scientific Institution «North Caucasian Federal Scientific Center of \\ Horticulture, Viticulture, Wine-making», 39 str. 40 Let Pobedy, Krasnodar, 350901, Russia
}

\begin{abstract}
As a result of the studies, species-specific reactions of strains of the genus Fusarium Link of relative sensitivity to the active substances of chemical fungicides, in vitro, were noted. The drugs showed both very high biological effectiveness (BE) $(100 \%)$ and very low $(0 \%)$. In suppressing the species $F$. sporotrichioides, the best result was shown by a mixed preparation based on fluopyram and pyrimethanil, as well as singlecomponent - mefentrifluconazole and cyprodinil, for the species F. oxysporum - all three mixed preparations: fluopyram + pyrimethanil; tebuconazole + fluopyram and thiram + difenoconazole. It can be preliminarily concluded that the same active substances and their mixtures exhibit unequal activity against different strains of the same species from the genus Fusarium, the causative agent of apple core rot.
\end{abstract}

\section{Introduction}

In the conditions of modern horticulture, plant protection from diseases and pests is one of the important elements of fruit production technology. More than 30 dangerous pathogens develop on an apple tree, which annually under favorable conditions can lead to a loss of yield or a significant decrease in its quality [1-3].

Changing weather conditions increase the harmfulness of the dominant diseases, and also lead to the emergence of new harmful species. The epiphytotic development of diseases such as scab and powdery mildew is observed almost every year in the gardens of the Krasnodar Region. In the last 15 years, the prevalence of pathogens of the genus Fusarium Link has increased in the region; they are found both in the root rot pathocomplex and in the apple fruit core rot pathocomplex, and their harmfulness increases every year [4-9].

As you know, the main method of protecting an apple tree from mycopathogens is chemical, however, the constant use of fungicides of chemical origin leads to a decrease in the effectiveness of drugs, the appearance of resistance in pathogens and a violation of the ecological balance in the agrocenosis of an apple orchard. To develop protective measures,

\footnotetext{
*Corresponding author: galyayaku@gmail.com
} 
it is necessary to identify the most dangerous and new harmful objects, as well as to select drugs with high efficiency and, preferably, low consumption rates. It is not always possible to assess the effectiveness of chemical inhibition of a particular fungus species; in addition, as mentioned above, many phytopathogens can acquire a certain level of resistance to fungicides. For this reason, it becomes necessary to study the effectiveness of drugs in relation to certain species using laboratory methods and fungi pure cultures. The in vitro method allows in a fairly short time to assess the effectiveness of chemicals against pathogens [10-11].

Purpose of the study: to determine the effectiveness of fungicides of chemical origin in vitro against strains of some species of the genus Fusarium isolated in 2021, causative agents of rot of the core of apple fruits.

\section{Materials and methods}

The studies were carried out in 2021 in the laboratory of biotechnological control of phytopathogens and phytophages of the Federal State Budgetary Scientific Institution SKFNTSSVV. The objects of the study were the active substances of modern fungicides, consisting of one or two components, under the numbers:

1) $125 \mathrm{~g} / 1$ fluopyram $+375 \mathrm{~g} / 1$ pyrimethanil;

2) $200 \mathrm{~g} / 1$ tebuconazole $+200 \mathrm{~g} / 1$ fluopyram;

3) $400 \mathrm{~g} / \mathrm{l}$ of thiram $+30 \mathrm{~g} / 1$ of difenoconazole;

4) $800 \mathrm{~g} / \mathrm{kg}$ of thiram;

5) $75 \mathrm{~g} / 1$ of mefentrifluconazole.

Their biological effectiveness was assessed in the work. Control - distilled, autoclaved water, standard - active ingredient cyprodinil containing $750 \mathrm{~g} / \mathrm{kg}$ in the preparation. Solutions of active substances of fungicides were prepared from the calculation of the concentrations recommended by the manufacturer for use, according to the method of Chekmarev V.V. [12]. Aqueous solutions of the preparations were prepared on the day of the experiment and used fresh. In each Petri dish, $300 \mu \mathrm{l}$ of an aqueous solution of the drug or water was applied, evenly distributed with a sterile glass spatula over the surface of nutrient agar.

In the experiment, we used monoconidial strains of Fusarium sporotrichioides and Fusarium oxysporum, pathogens of apple core rot, isolated from industrial garden plantations of the Krasnodar Region in 2021 from symptomatic fruits. The strains were inoculated with a small piece of air mycelium injected into the center of a Petri dish on a PGA medium (potato-glucose agar) in triplicate. The obtained crops were placed in a thermostat for 7 days and incubated at $25^{\circ} \mathrm{C}$. All procedures related to manipulation with pure cultures were performed under sterile conditions. The criterion for evaluating the biological effectiveness $(\mathrm{BE})$ of the preparations was the average growth rate $(\mathrm{cm})$ of the fungal colony (aerial mycelium), which was analyzed according to the generally accepted method [12].

\section{Results and discussion}

As a result of the research, it was found that the studied active substances of the fungicides showed different activity in relation to the analyzed species of the genus Fusarium (table 1).

On the 7th day of fungi growth, the diameter of the culture ranged from $0 \mathrm{~cm}$ to $7.8 \mathrm{~cm}$. The F. sporotrichioides strain turned out to be the fastest growing culture in the experiment. It should be noted that the culture of the pathogen under the influence of drugs 
in most cases did not change its morphological and cultural characteristics, with the exception of the standard (№ 6), mixed preparation № 3 and mefentrifluconazole (№ 5).

Under the influence of cyprodinil, the color of the aerial mycelium changed, instead of pink it was white. On a mixed preparation, the strain released a brown pigment into the medium; Mefentrifluconazole led to the development of a denser mycelium, and also changed the color of the edge of the culture to dark red, in contrast to light pink or beige in the control (Figure 1).

Table 1. Influence of fungicides on the growth of fungi of the genus Fusarium in vitro, 7 th day after sowing.

\begin{tabular}{|c|l|c|c|c|c|}
\hline \multirow{2}{*}{ № } & \multicolumn{1}{|c|}{ Experience Option } & \multicolumn{2}{|c|}{ Fusarium sporotrichioides } & \multicolumn{2}{|c|}{ Fusarium oxysporum } \\
\cline { 3 - 6 } & $\begin{array}{c}\text { Culture } \\
\text { diameter, } \mathrm{cm}\end{array}$ & $\mathrm{BE} \%$ & $\begin{array}{c}\text { Culture diameter, } \\
\mathrm{cm}\end{array}$ & BE, $\%$ \\
\hline & Control & 7.6 & - & 5.5 & - \\
\hline 1 & $\begin{array}{l}125 \mathrm{~g} / 1 \text { fluopyram }+ \\
375 \mathrm{~g} / 1 \text { pyrimethanil }\end{array}$ & 0.0 & 100 & 1.6 & 70.9 \\
\hline 2 & $\begin{array}{l}200 \mathrm{~g} / 1 \text { tebuconazole }+ \\
200 \mathrm{~g} / 1 \text { fluopyram }\end{array}$ & 4.5 & 40.7 & 1.2 & 78.1 \\
\hline 3 & $\begin{array}{l}400 \mathrm{~g} / 1 \text { thiram }+ \\
30 \mathrm{~g} / 1 \text { difenoconazole }\end{array}$ & 3.2 & 57.8 & 1.3 & 76.3 \\
\hline 4 & $800 \mathrm{~g} / \mathrm{kg}$ thiram & 7.8 & 0 & 3.7 & 32.7 \\
\hline 5 & $75 \mathrm{~g} / 1$ mefentrifluconazole & 2.0 & 73.6 & 2.0 & 63.6 \\
\hline 6 & $\begin{array}{l}750 \mathrm{~g} / \mathrm{kg} \text { cyprodinil } \\
\text { (standard) }\end{array}$ & 2.2 & 71.0 & 2.2 & 60.0 \\
\hline
\end{tabular}

The most effective against this fungus was shown by a mixed preparation based on fluopyram and pyrimethanil, which suppressed its growth by $100 \%$, which turned out to be higher than the efficiency of the standard represented by cyprodinil. Analyzing the effectiveness of the mixed preparation, it can be assumed that the greatest contribution to it is made by the component - pyrimethanil, belonging to the same chemical class as the active substance of the standard - anilinopyrimidines. In addition, the second component of the mixture, fluopyram, was present in the composition of another formulation (№ 2), together with tebucanosol, which showed a biological effectiveness below $50 \%$. The third formulation containing thiram and difenoconazole was slightly more effective than the second formulation. It can be assumed that its activity was determined exclusively by the triazole component, since thiram, in one-component preparation № 4, had no effect on the growth of the $F$. sporotrichioides isolate. Efficiency slightly higher than the control was also shown by a new promising active ingredient from the class of triazoles mefentrifluconazole.

In relation to the $F$. oxysporum isolate, all three mixed preparations showed the highest efficiency, while the efficiency of the standard fungicide was higher. The lowest activity was noted for the variant with the active ingredient tyram, as well as for the previous isolate of the genus Fusarium. 


\section{Fusarium sporotrichioides}

Control

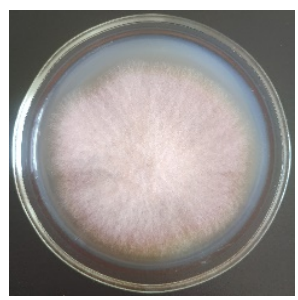

№ 1

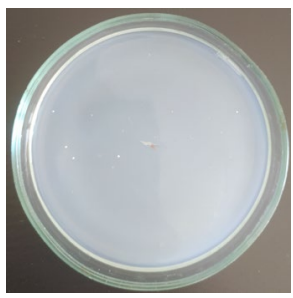

№ 3

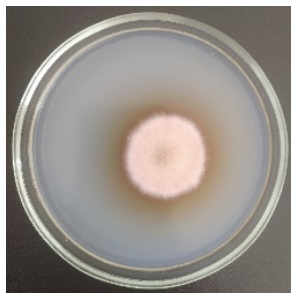

Standard

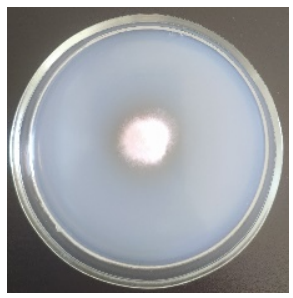

№ 2

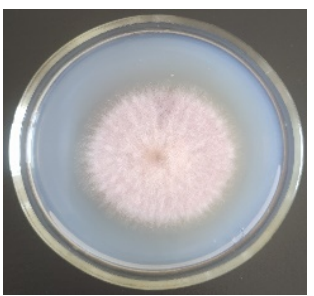

№ 4

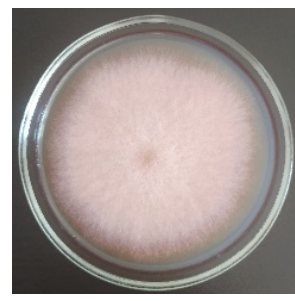

\section{Fusarium oxysporum}

Control

Standard

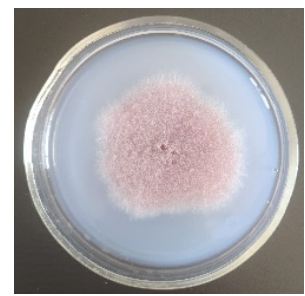

№ 1

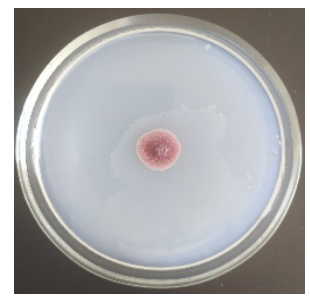

№ 3
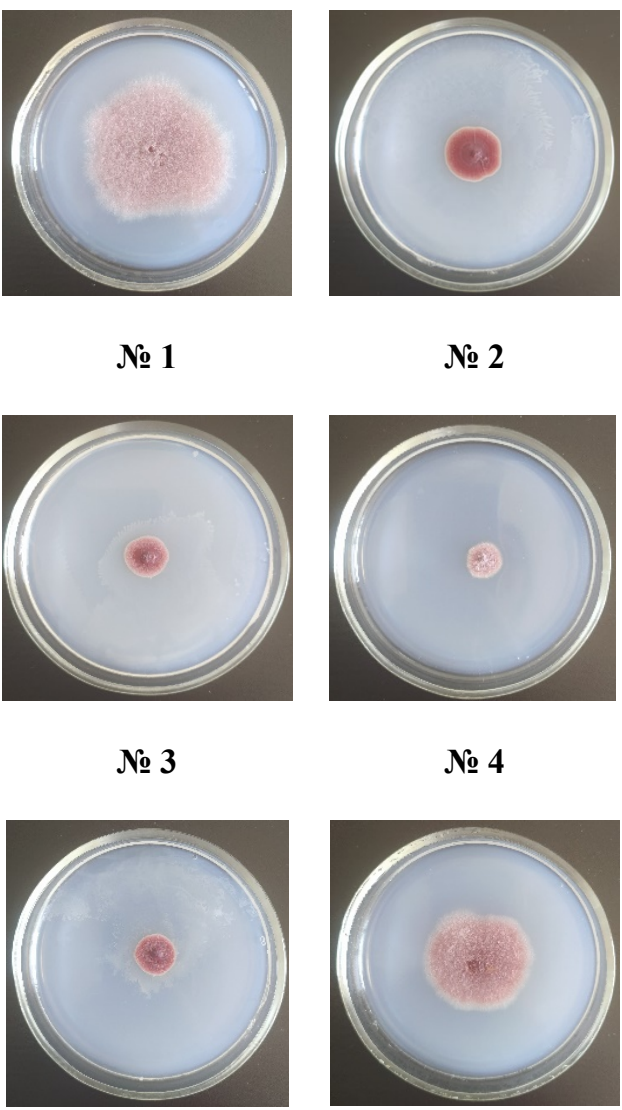

№ 2

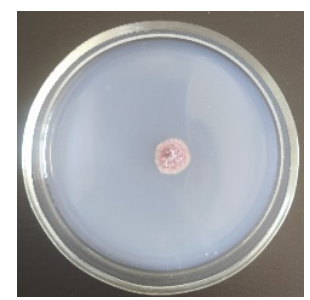

№ 4

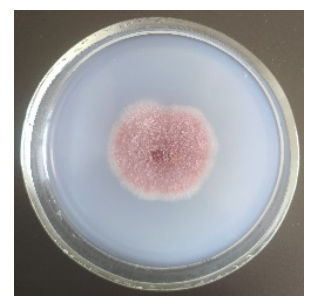

№5
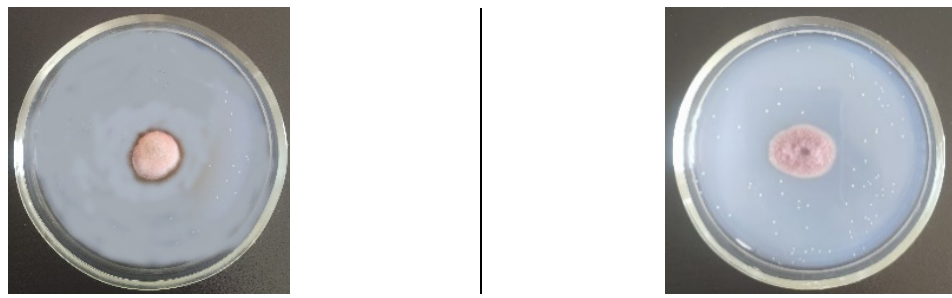

Fig. 1. Influence of active ingredients of fungicides on the growth of fungi of the genus Fusarium in vitro, 7 th day after sowing

However, the effectiveness of suppressing the growth of F. oxysporum culture of all formulations was insufficient.

The $F$. oxysporum culture under the influence of almost all drugs changed its morphological and cultural characteristics. Variants of formulations № 1, 2, 3 and 6 were characterized by a change in the color of the aerial mycelium from pink to dark red and its 
denser texture. Under the influence of thiram, the morphological and cultural characteristics of this isolate were indistinguishable from the control (Figure 1).

It should be noted that we have already noted species-specific reactions regarding the sensitivity to chemical fungicides of other strains of the genus Fusarim, causative agents of apple core rot, isolated in 2019-2020. Fungicide Cidely-Top, DC (125 g / 1 difenoconazole + $15 \mathrm{~g} / 1$ ciflufenamide) inhibited the growth of strains $F$. sporotrichioides, $F$. semitectum and $83 \%$ F. oxysporum by 95-96 \%. Fungicide Luna Tranquility, SC (125 g / 1 fluopyram + $375 \mathrm{~g} / 1$ pyrimethanil) showed $100 \%$ antifungal activity against strains of the species $F$. avenacium, $F$. oxysporum and medium against $F$. solani. The drug Tirada, CE (400 g / 1 of thiram $+30 \mathrm{~g} / 1$ of difenoconazole) suppressed the growth of strains of all the listed micromycetes by $98-100 \%$. A higher efficiency against a greater number of species of causative agents of rot of the core of apple fruits was noted in preparations containing a compound from the group of triazoles as one of the active substances [10].

\section{Conclusion}

As a result of the studies, species-specific reactions were noted regarding the sensitivity to the active substances of fungicides of chemical genesis of strains of the genus Fusarium in vitro. The active substances showed both very high biological effectiveness $(100 \%)$ and low, or its complete absence $(0 \%)$.

In suppressing the species $F$. sporotrichioides, the best result was shown by a mixed fungicide based on fluopyram and pyrimethanil, as well as single-component preparations based on the active ingredients mefentrifluconazole and cyprodinil, for the species F. oxysporum - all three mixtures containing: fluopyram + pyrimethanil; tebuconazole + fluopyram; thiram + difenoconazole. It can be preliminarily concluded that the same active substances and their mixtures exhibit unequal activity against different strains of the same species from the genus Fusarium, the causative agent of apple core rot.

\section{References}

1. V. Florian, C. Puia, G. Radu, T. Florian, L. Suciu, GeoConference SGEM 2018, Conference proceedings, 699-706 (2018) DOI: 10.5593/sgem2018/6.2/S25.092

2. P. É. Lauri, B. Pitchers, L. Dufour, S. Simon, Acta Horticulturae 1281, 307-321 (2020) DOI: 10.17660/ActaHortic.2020.1281.42

3. S. Gašić, B. Tanović, Pesticidi i Fitomedicina, 28 (2), 97-102 (2013) DOI: 10.2298/PIF1302097G

4. I. L. Astapchuk, G. V. Yakuba, A. I. Nasonov, BIO Web of conferences, 7, 00005, (2020)

https://www.bioconferences.org/articles/bioconf/full_html/2020/05/bioconf_bpp 2020_00005/bioconf_bpp2020_00005.html

5. I. L. Astapchuk, A. I. Nasonov, BIO Web of Conferences, 34, 04012 (2021) https://doi.org/10.1051/bioconf/20213404012

6. W. Gongshuai, Y. Chengmiao, P. Fengbing, W. Xiaobao, X. Li, W. Yanfang, W. Jinzheng, T. Changping, C. Jie, M. Zhiquan, Horticultural Plant Journal 4 (5), 175-181, (2018) https://www.sciencedirect.com/science/article/pii/S2468014118301468

7. M. Kelderer, L. Manici, F. Caputo, M. Thalheimer, Plant Soil 357, 381-393, (2012) https://link.springer.com/article/10.1007/s11104-012-1172-0

8. W. Botha, M. Mazzola, C. Spies, 130 (2), 215-229, (2011) https://www.researchgate. net/publication/225480437_Characterization_of_fungi_Fusarium_and_Rhizoctonia_an 
d_oomycetes_Phytophthora_and_Pythium_associated_with_apple_orchards_in_South Africa

9. M. Sharma, A. Kapatia, S. Kulshrestha, Biosciences biotechnology research Asia, 13(1), 463-468, (2016) http://www.biotech-asia.org/vol13nol/analysis-of-geneticdiversity-amongst-fusarium-spp-associated-with-root-rot-of-apple/

10. S. Mannai, N. Horrigue-Raouani, N. Boughalleb-M'Hamdi, 1-2, 14-34, (2018) https://www.researchgate.net/publication/336848028_Characterization_of_Fusarium_s pecies_associated_with_apple_decline_in_Tunisian_nurseries

11. I.L. Astapchuk, G.V. Yakuba, A.I. Nasonov, E3S Web of conferences, 285, 03015, (2021) https://doi.org/10.1051/e3sconf/202128503015

12. A. Orina, O. Gavrilova, T. Gagkaeva, BIO Web of Conferences 18, 00022 (2020) https://www.researchgate.net/publication/339745317_The_effect_of_fungicides_on_gr owth_of_Fusarium_fungi_in_vitro

13. V.V. Chekmarev, Methodology for determining the biological effectiveness of fungicides against fungi of the genus Fusarium and their resistance to chemical preparations, (2015) https://www.elibrary.ru/download/elibrary_35307475_46783273 .pdf 